\title{
Profile of Inflammatory Bowel Disease from a Tertiary Care Center in North East India
}

\author{
Anjan Jyoti Talukdar*
}

Department of Medicine, Gauhati Medical College and Hospital, Bhangagarh, Guwahati, Assam, 781 032, India

Received: August 17, 2017; Accepted: September 25, 2017; Published: March 29, 2018

*Corresponding author: Anjan Jyoti Talukdar, Department of Medicine, Gauhati Medical College and Hospital, Bhangagarh, Guwahati, Assam, 781 032, India, Email: dranjan_t@yahoo.co.in

Inflammatory Bowel Disease was believed to be unknown in India about 20 years ago. But several reports have been published which shows that its prevalence in India is not that uncommon as perceived.

Reports from North East India on IBD are rare. Keeping this in mind an effort was made to collect data on IBD in a tertiary care hospital in North East India.

\section{Ulcerative Colitis}

The hospital prevalence of UC patients was found to be $22.9 / 100,000$ patients. The mean duration from the onset of symptoms to diagnosis was less than a year. Male to female ratio was $1.45: 1$.

Of our Ulcerative Colitis patients, $45 \%$ had extensive disease; left sided disease was seen in $37 \%$, procto-sigmoid involvement was seen in $18 \%$ and no patients had isolated proctitis. Only arthralgia was present as an extra-intestinal manifestation in $11.11 \%$ patients. Surprisingly we did not encounter any other extra-intestinal manifestation.
On presentation moderate disease was seen in 59\%, 15\% had mild disease and severe disease was seen in $26 \%$.

Majority (65\%) of our patients required steroids for remission and only $35 \%$ patients responded to 5-ASA alone.

\section{Crohns Disease}

The hospital prevalence of Crohn's Disease in our study was 9.4 per 100,000 patients. The mean duration of symptoms before diagnosis was about 2 years.

The common symptoms were abdominal pain (90\%), loose stools (63\%) and weight loss (63\%),. Extra-intestinal manifestations were seen in $27 \%$ patients in the form of arthralgia.

$73 \%$ patients had small intestinal disease and $27 \%$ had ileocolonic disease. No patients had only colonic involvement.

$64 \%$ of the patients required steroids for remission.

Striking difference was the pattern of gut involvement in Crohn's disease where majority of our patients had small intestinal involvement.

Table 1: Ulcerative Colitis: Extent and Severity in comparison to different centers in India

\begin{tabular}{|c|c|c|c|c|c|}
\hline Region & $\begin{array}{c}\text { Procto- } \\
\text { Sigmoid (\%) }\end{array}$ & Left Sided (\%) & Pancolitis (\%) & $\begin{array}{c}\text { Mild disease } \\
\text { (\%) }\end{array}$ & $\begin{array}{c}\text { Moderate disease } \\
\text { (\%) }\end{array}$ \\
\hline Our study & 18 & 37 & 45 & 15 & 26 \\
\hline Sood et al Ludhiana & 25 & 47 & 28 & 15 & 30 \\
\hline $\begin{array}{c}\text { Kochar et al } \\
\text { Chandigarh }\end{array}$ & 18 & 41 & 41 & 14 & 25 \\
\hline Nigam et al Gorakpur & 34 & 46 & 20 & 47 & 39 \\
\hline
\end{tabular}

Table 2: Crohn's Disease: Presenting Features in comparison to different centers in India

\begin{tabular}{|c|c|c|c|c|c|c|c|}
\hline Region & Diarrhoea (\%) & $\begin{array}{c}\text { Abdominal pain } \\
(\%)\end{array}$ & Weight loss (\%) & Fever (\%) & Mass (\%) & $\begin{array}{c}\text { Rectal bleed } \\
(\%)\end{array}$ & $\begin{array}{c}\text { Arthralgia } \\
(\%)\end{array}$ \\
\hline Our study & 63 & 90 & 63 & 27 & 0 & 27 & 12 \\
\hline Philip et al & 70 & 71 & --- & 37 & --- & 41 & 12 \\
\hline Polimoo e t a l Vellore & 64 & 46 & 37 & -- & 13 & -- & 22 \\
\hline Tandon et al & 76.4 & 94.1 & 88.2 & --- & --- & --- & --- \\
\hline
\end{tabular}


Table 3: Crohn's Disease: Pattern of gut involvement in comparison to different centers in India

\begin{tabular}{|c|c|c|c|c|c|}
\hline Region & Colon alone $(\%)$ & Small bowel alone (\%) & Both involved (\%) & Ileo-colonic (\%) & Rectal Alone (\%) \\
\hline Our study & 0 & 72 & 0 & 28 & 0 \\
\hline Polimoo et al Vellore & 50 & ---- & --- & $60-70$ & --- \\
\hline Amrapurkar \& Patel & 25 & 10 & 65 & 60 & 20 \\
\hline Philip et al Kochi & 35 & 20 & 45 & --- & 18 \\
\hline Tandon et al Delhi & 53 & -- & 47 & -- & -- \\
\hline
\end{tabular}

\section{Referesnces}

1. Sood A, Midha V, Sood N, Kaushal V. Self reported disease awarenessa questionnaire survey of ulcerative colitis patients. Indian J. Gastroenterol 2001;20(1):6-8.

2. Kochar R, Kumar P, Niyanmuttalah S, Nagi B, Mehta SK. Extra-intestinal manifestations in patients of idiopathic ulcerative colitis (IUC) in Northern India. Indian J Gastroenterol. 1995;10(3):88-89.

3. Nigam P, Mishra RKC, Kapoor KK, Nigam P, Sarkari A, Sarkari NBS. Indian J. Gastroenterol 1995(suppl 2) A52.

4. Philip M, Augustine P, Ramsh GN, Pushpa M, Ramesh H, Mukkada RJ, et al. Analysis of Crohn's disease in a tertiary referral hospital - a disease believed to be rare in India. Indian J Gastroenterol 2001;20(suppl 2): A18.
5. Peter S, Pulimood A, Patra S, Kurian G, Ramakrishna BS, Chandy G. Crohn's disease - a 10 year retrospective analysis. Indian J. Gastroenterol. 1999;18 (suppl 2): A6.

6. Tandon RK, Makharia GK, Duttagupta S, Garg PK. Crohn's disease: results of a clinical radiological and endoscopic study in a tertiary care center in India. Indian J. Gastroenterol. 2001;20(suppl2):A60-61.

7. Amarapurkar D, Patel N. Crohn's disease in India. Gastroenterology Today. 2002;6: 73-75. 